Research Article

\title{
Thermal Response and Degressive Reaction Study of Oxo-Biodegradable Plastic Products Exposed to Various Degradation Media
}

\author{
S. M. Al-Salem ${ }^{D},{ }^{1}$ A. Y. Al-Nasser, ${ }^{1}$ M. H. Behbehani, ${ }^{1}$ H. H. Sultan, ${ }^{1}$ H. J. Karam, \\ M. H. Al-Wadi, ${ }^{1}$ A. T. Al-Dhafeeri, ${ }^{2}$ Z. Rasheed, ${ }^{1}$ and M. Al-Foudaree ${ }^{1}$ \\ ${ }^{1}$ Environment \& Life Sciences Research Centre, Kuwait Institute for Scientific Research, P.O. Box: 24885, Safat 13109, Kuwait \\ ${ }^{2}$ Water Research Centre, Kuwait Institute for Scientific Research, P.O. Box: 24885, Safat 13109, Kuwait \\ Correspondence should be addressed to S. M. Al-Salem; ssalem@kisr.edu.kw
}

Received 12 January 2019; Revised 15 March 2019; Accepted 26 March 2019; Published 30 April 2019

Academic Editor: Cornelia Vasile

Copyright (C) 2019 S. M. Al-Salem et al. This is an open access article distributed under the Creative Commons Attribution License, which permits unrestricted use, distribution, and reproduction in any medium, provided the original work is properly cited.

In this work, three plastic film products commonly used as commodity thermoplastic articles were analysed with the aim of characterizing their thermal behaviour and stability. The test specimens were subjected to a series of analytical tests to confirm their biodegradable nature. The specimens ranged between 30 and $70 \mu \mathrm{m}$ in thickness and showed high concentrations of regulated metals, namely, lead $(\mathrm{Pb})$, postchemical analysis which can lead to its migration to natural sinks. The specimens were also exposed to degressive media, namely, accelerated (UV induced) weathering and soil burial field testing. The weight loss measured exceeded 58\% after soil burial indicating deterioration under natural environmental stressors. In addition, the thermal characterization campaign executed with the aim of determining the product's thermal response followed internationally recognised experimental protocols for the determination of thermal stability. The methodology used followed the International Confederation for Thermal Analysis and Calorimetry (ICTAC) recommendation for thermal stability and the computation of kinetic parameters. The degradation reaction kinetics were also determined postexposure to degressive media. Thermogravimetric analysis coupled with differential scanning calorimetry heat flow analysis and Fourier infrared spectroscopy results was also used in studying the degradation behaviour of the specimens. Analytical kinetic estimation methods relying on model free solutions enabled the determination of the apparent activation energy $\left(E_{\mathrm{a}}\right)$ of the specimens postexposure to degradation media. A shift in the degradation mechanism was also detected after studying the kinetic parameters which showed a range of $E_{\mathrm{a}}$ between 86.64 and $226.90 \mathrm{~kJ} \mathrm{~mol}^{-1}$ depending on the type of specimens and exposure media. It can be concluded that the oxo-biodegradable films are well suited for thermal treatment in the future as discarded plastic solid waste (PSW) articles. This work also paves the way for developing national standards and future plans for societies burdened with PSW accumulation.

\section{Introduction}

The accumulation of micro- and macroplastic materials alike has led to an overwhelming impact on the environment. Plastics are noted to be an essential commodity to our daily functions. They are versatile with excellent compounding, mechanical, and insulation properties. They are also characterized with a nondegradable behaviour in open environments. However, the increasing demand of consumers forced various countries and authorities to start considering alternative strategies to mitigate plastic pollution. It is estimated that nondegradable plastics accumulate on a global basis (in natural sinks) at a rate of 25 million tonnes per annum [1]. The United States Environmental Protection Agency (USEPA) has announced that 236 million tonnes of municipal solid waste (MSW) was generated on US soil back in the year 2003. The plastic solid waste (PSW) fraction was estimated to be $11.3 \%$ of the total solid waste (SW) load. The majority of this PSW has accumulated in open/urban environment or landfilled [2]. 


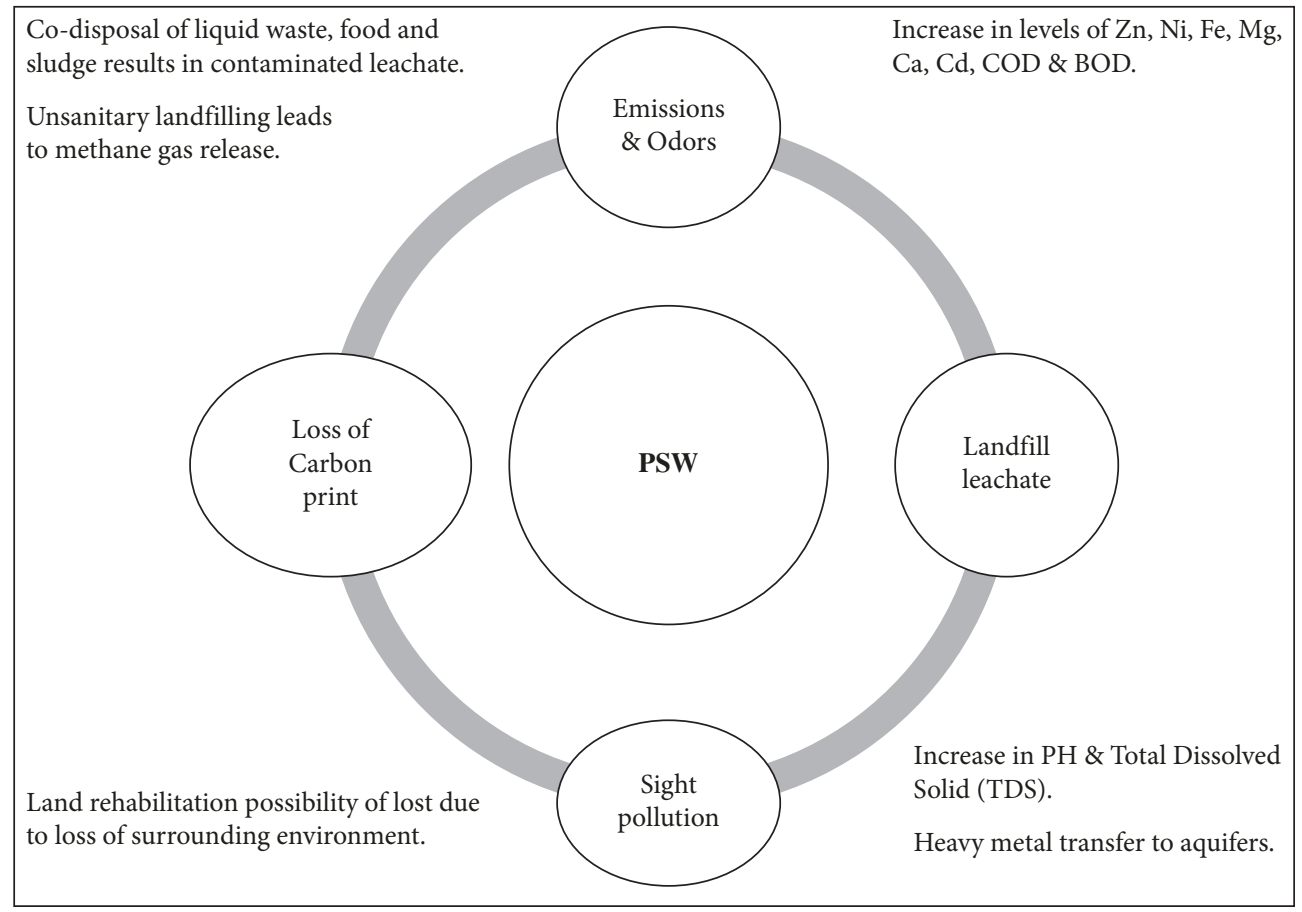

FIGURE 1: Associated environmental burdens of unsanitary landfilling and/or mismanaged plastics.

The build-up of PSW leads to a number of adverse environmental and health-related effects. These could be summarised as heavy metal migration to natural sinks, gaseous emissions, and release of toxins and finally the loss of carbon from the nonrecoverable fraction of plastics in the form of energy and chemicals [3,4]. Figure 1 summarises the main environmental burdens associated with plastic pollution and mismanagement. PSW could be treated and recycled using various techniques, following the PSW management hierarchy previously depicted in Al-Salem et al. [5]. These technologies can transform plastics into various market-grade products, chemicals, and fuel that can result in the reduction of the mismanaged portion of the plastics in industrial/use flow.

The majority of consumers' demand on plastic resin is oriented towards polyolefin (PO) polymers. High-density polyethylene (HDPE), low-density polyethylene (LDPE), and linear low-density polyethylene (LLDPE) alone occupy over $37 \%$ of the US market demand [2]. These grades are typically used for the packaging sector and are nondegradable by nature. Therefore, it is essential to start advocating techniques and technologies that can reduce the bulk of plastics by promoting degradation routes of plastics. Biodegradation is one of those techniques that compete with PSW recycling and recovery as an alternative route for plastic waste management. Biodegradation of plastics can be achieved via a number of methods. The biodegradability of the constituting polymers of the plastic product can be enhanced by blending them with natural substances (materials) such as starch, chitin, or cellulose [6]. These materials are termed as biobased plastics and classed as hydrobiodegradable polymers. Natural resources, food supplies, and vast land space are consumed during the production of the raw material for the compounding of hydrobiodegradables. This raises a claim on the fact that such processes utilize natural resources that are best suited for human consumption and urban development. The second method that renders a plastic material as a biodegradable one can be achieved by mixing prodegradants (i.e., prooxidants) with the polymer. These additives contain various transition metals such iron $(\mathrm{Fe})$, manganese $(\mathrm{Mn})$, calcium $(\mathrm{Ca})$, and cobalt $(\mathrm{Co})$ [7]. Their aim is to increase the rate of oxidation with air leading to the cleavage of the $\mathrm{PO}$ under heat and/or light.

There exist a number of obstacles in transforming common commodity PO plastics into biodegradable ones, leaving behind nothing but carbon dioxide $\left(\mathrm{CO}_{2}\right)$, water, and humus. PO polymers are hydrophobic which makes them resistant to hydrolysis in the first place. This is due to their chemical structure being of a long-chain hydrocarbon (HC), namely, $\mathrm{CH}_{2}$. The insertion of hydrophilic groups as a result of an initial chemical or physical degradation will result in the insertion of hydrophilic groups on the polymer's surface [1]. After which, microorganisms will start growing by using the polymeric backbone as a carbon source. In addition, PO manufacturers typically use antioxidants and light transforming (LT) additives during the manufacturing of commercial-grade resins. These are used to give the plastic articles strength and more integrity for various indoor/ outdoor applications $[8,9]$. Furthermore, PO polymers possess a high molecular weight (MW) that ranges between 4,000 and $28,000 \mathrm{~g} \mathrm{~mol}^{-1}$ [1]. Biodegradable polymers will have a MW of $500 \mathrm{~g} \mathrm{~mol}^{-1}$ or less [10]. Therefore, it is essential to consider the abovementioned factors when the development of a biodegradable polymer takes place. The addition of renewable or prooxidant additives must initiate 
the long polymeric chain breakdown. This will result in producing oligomers, dimmers, or monomers that can have these microorganisms feed on as a carbon and energy source.

Various countries have started implementing obligatory regulations that govern the use of biodegradable plastic products. A leading example is the United Kingdom (UK) where majority of plastic carrier bags used by consumers is of biodegradable nature. On the other hand, countries within the Middle East (ME) region have just started to take such matters in a more serious manner. A prime example is the State of Kuwait noted for being the highest MSW generation country in the world [11]. The MSW generation rate has reached an alarming rate of $5.7 \mathrm{~kg}$ per capita per day, out of which plastics make up over $16 \%[9,12]$. Past research work has focused on the behaviour of oxo-biodegradables in marine environments and soil burial conditions. The aim was typically devoted to assessing the toxicity level and impact on local environments. Markowicz et al. [13] have recently evaluated ten different grades of polymers including oxo-biodegradable films. The aim of their work was to determine the material's applicability for composting and potential impact on the environment. The work showed the inapplicability of prooxidant-filled polymers with heavy metal content for industrial composting. Possible release of metals in the environment also shows possible alarming threat to materials postcomposting or treatment. This inapplicability for composting was also previously declared by Camann et al. [14]. Requejo and Pajarito [15] studied LDPE oxo-biodegradable films in water. The monitored parameters include $\mathrm{pH}$ level, total dissolved solids, and oxidationreduction potential. The results indicated that over the period of 49 days of continuous monitoring, the water quality has drastically decreased. Various oxo-biodegradable grades were also tested by seawater immersion over a prolonged period of time (180 days) by Nazareth et al. [16]. Majority of tested samples showed no evidence of degradation by studying their infrared (IR) spectra including polyethylene (PE) plastic bags, which was deemed as a misleading choice for environmentally concerned consumers.

Ojeda et al. [17] examined commercial oxo-plastic products found on the Brazilian market postexposure to environmental conditions. The studied samples have shown a degree of mineralization after three months of incubation with compost especially with highly saturated environments. The conventional PE films exhibited a slow degradation behaviour. Nikolić et al. [18] studied LLDPE formulations with nano titania under various environmental stressors including soil and influential parameters such as moisture and organic matter. It was noted that by comparison to poly(butylene adipate-co-terephthalate) (PBAT) (trade name Ecoflex), fungi play a major role in the biodegradation rather than bacteria. This was confirmed by the DNA analysis conducted. It was also concluded that photochemical reactions of PBAT are the dominating factor in the UVinduced degradation. By observing past results within this research area, very few have attempted to examine the alteration of thermal response and stability of such material (e.g., oxo-biodegradable plastics) postexposure to various environmental conditions. However, in majority of cases
TABLE 1: Types and description of plastic bags considered for testing. Adapted from Al-Salem et al. [21].

\begin{tabular}{lcc}
\hline $\begin{array}{l}\text { Sample code by } \\
\text { type/colour }\end{array}$ & $\begin{array}{c}\text { Average thickness } \\
\text { (per test specimen) }\end{array}$ & $\begin{array}{c}\text { Typical market } \\
\text { application }\end{array}$ \\
\hline $\begin{array}{l}\text { Type I (yellow) } \\
\text { Type II (blue) }\end{array}$ & $70 \mu \mathrm{m}$ & $\begin{array}{c}\text { Trash bag } \\
\text { Type III }\end{array}$ \\
$\begin{array}{l}\text { (translucent/white) } \\
\text { Reference PE bag } \\
\text { (translucent/white) }\end{array}$ & $30 \mu \mathrm{m}$ & Carrier bag \\
\hline
\end{tabular}

reviewed, it was noted that the local environment plays a major role in the alteration of properties with time. The recyclability of such materials in thermal units and the changes in thermal stability also play a crucial role in determining the optimal treatment method as a PSW end of pipe solution.

There are no governing standards or regulations for the use of biodegradable plastics within Kuwait. Therefore, and as a cornerstone baseline study, it is essential to initiate the work revealed in this paper. In this work, three biodegradable plastic bags were secured from local sources within the state. The main objective is to study and reveal the nature of the plastic products, whilst verifying the claims of the supplying companies. The plastic bags are exposed to various routes of degradation, in order to determine their biodegradability under various environmental conditions. This was conducted to aid local government authorities in standardising the practices for such commodity products. A secondary objective of the work revolves around determining the thermal response and applicability of these products for thermal and thermochemical recycling technologies (e.g., incineration, pyrolysis, and gasification). These technologies are arguably the most beneficial in terms of environmental burden reduction and ecumenical return rate $[19,20]$. Therefore, it is of immense importance to establish a baseline of thermal characteristics for such products of which scientific literature lacks. The work shown in this communication paves the way for determining the behaviour of biodegradble plastic filmsunder various under various degradation media, designed to have governing standards on a state level.

\section{Materials and Methods}

2.1. Sample Acquirement and Assessment. Three types of plastic bags used in the Kuwaiti market were secured with their main characteristics depicted in Table 1. The samples acquired were presumed to be environmentally friendly and biodegradable, which were secured from various sources within the state (Figure S1). The three types of the plastic bags are the most dominant degradable plastic types in the local market. The samples were cut into standard testing dimension specimens accepted by international protocols for thin plastic film characterization as described previously [21]. A reference polyethylene (PE) bag obtained from a commercial outlet source in the UK was also analysed for comparative assessment. The reference material was 
used as received and was clear/transparent in appearance with a reported melting point of $129^{\circ} \mathrm{C}$. For confidentiality reasons, the company name was left out of this communication.

\subsection{Fourier Transformed Infrared Spectrometry (FTIR). An} IS10 Thermo-Nicolet FTIR unit equipped with an attenuated reflectance (diamond) attachment was used for the analysis and the identification of the material's chemical fingerprint. The test was conducted in accordance with ISO 10640 [22]. Samples were tested using 32 scans for the background and each individual spectrum in a spectral range of 4000 to $400 \mathrm{~cm}^{-1}$.

\subsection{Crystallinity Measurements Using Differential Scanning Calorimetry (DSC) and Thermogravimetry. A Shimadzu} DSC (Model 60 Plus Series) was used to test control and exposed samples using $2 \pm 0.1 \mathrm{mg}$ samples taken from the middle section of the film specimens. Aluminium oxide $\left(\mathrm{Al}_{2} \mathrm{O}_{3}\right)$ crucibles were used for both samples and reference material experimental runs. Crystallinity measurements were determined using scans of the first and second heating cycles between 50 and $230^{\circ} \mathrm{C}$ based on the peak area of the heat flow curve between $60^{\circ} \mathrm{C}$ and $130^{\circ} \mathrm{C}$ with a nitrogen $\left(\mathrm{N}_{2}\right)$ gas flow rate of $20 \mathrm{ml} \mathrm{min}^{-1}$ and a heating rate of $10^{\circ} \mathrm{C} \mathrm{min}^{-1}$. The cooling rate was set at $15^{\circ} \mathrm{Cmin}^{-1}$ in similar conditions $[23,24]$. The second heating cycle was included in the crystallinity analysis following the initial heating run, as it will eliminate inherited effects of thermal histories and weathering on the specimens. The degree of crystallinity (\%) was calculated from the software by dividing the melting enthalpy over the melting enthalpy of a $100 \%$ crystalline PE $\left(293.6 \mathrm{~g} \mathrm{~J}^{-1}\right)$ for each heating cycle [25]. Thermal degradation of the samples was investigated using a Shimadzu TGA-50 thermobalance equipped with a data acquisition/analysis software (TA Instruments) set to record the data every second under five heating rates $(\beta)$ (i.e., 5, 10, 15, 20, and $25^{\circ} \mathrm{C} \mathrm{m^{-1 }}{ }^{-1}$. A constant flow of pure (99.99\%) dry nitrogen with a flow rate of $50 \mathrm{ml} \mathrm{min}^{-1}$ was maintained throughout the experiments. The measurements were conducted using $2 \pm 0.1 \mathrm{mg}$ samples from room temperature to $550^{\circ} \mathrm{C}$ made with triplicates showing high repeatability with standard deviation (std.) not exceeding $1 \%$ in accordance with the International Confederation for Thermal Analysis and Calorimetry (ICTAC) recommendations [26, 27] for nonisothermal (dynamic) thermogravimetry, to diminish sample size influences on the kinetics.

\subsection{Evolved/Pyrolysis Gaseous Product Analysis Coupled} with Gas Chromatography-Mass Spectrometry (GC/MS). A NETZSCH (Tarsus F3 Model) Thermogravimetric Analyser (TGA) was used for the determination of the thermal decomposition properties of the samples and inorganic content and the analysis of the evolved gases. Approximately, $10 \mathrm{mg}$ of specimens was cut out from the samples for the analysis. Samples were heated from room temperature (RT) to $900^{\circ} \mathrm{C}$ at a heating rate $(\beta)$ of $20^{\circ} \mathrm{C} \mathrm{min}^{-1}$. The TGA unit was calibrated using standard reference materials (e.g., tin, indium, and zinc) as per ISO 11358 [28]. The TGA unit was coupled with the FTIR IS10 Thermo Nicolet for the evolved gas analysis of the samples. The coupling was achieved with the use of a heated thermogravimetric infrared (TG-IR) transfer line from Thermo Nicolet (Figure S2). Combining the TGA with an infrared spectrometer enables the accurate characterization of the evolved compounds. In other words, TGA can reveal how much (quantity) and FTIR can reveal what (quality) is being evolved from a specimen. The gas cell and the transfer line were heated at approximately $200^{\circ} \mathrm{C}$, preventing any possible condensation of the evolved gases. The standard protocols of ASTM E2105 [29] were followed for the determination of volatiles evolved. Both the TGA and the FTIR units were controlled by a propriety software. FTIR scans were conducted with IR at a frequency of one scan per minute. The total absorption of the evolved gases analysed by the FTIR is represented by the GramSchmidt curve (GS). The GS curve is similar to the DTG (1st derivative TG) of the TGA thermogram. Specimens were heated from RT to $900^{\circ} \mathrm{C}$, and the gases were analysed in real time. The Gram-Schmidt graph was collected. The additives in the plastic bags were also investigated using an Agilent 7820A GC-Agilent 5977E MS Single quadrupole for pyrolysis gas analysis following the principles of ISO 21396 [30]. The unit is equipped with a HP5MS column with length of $30 \mathrm{~m}$, bore size of $0.25 \mathrm{~mm}$, and a stationary phase of 0.25 microns. A splitless injector was used at $280^{\circ} \mathrm{C}$, and the carrier gas used was hydrogen in a flow rate of $1.2 \mathrm{ml} \mathrm{min}^{-1}$.

2.5. ICP-MS/Additive Analysis. Inductively coupled plasma mass spectrometry (ICP-MS) was conducted after preparing the samples via microwave digestion with concentrated nitric acid $\left(\mathrm{HNO}_{3}\right)$ using ICP-OES Thermo ICAP 6000 series. The aim of the test was to determine the presence of inorganic metal additives (prodegradants) rooted within the plastic bags. General (total) metal screening including mercury $(\mathrm{Hg})$, arsenic $(\mathrm{As})$, cobalt $(\mathrm{Co})$, calcium $(\mathrm{Ca})$, nickel $(\mathrm{Ni})$, and lead $(\mathrm{Pb})$ was performed following ASTM D5673 [31] and ISO 11885 [32].

2.6. Degressive Media Exposure via Soil Burial and Accelerated Weathering. Soil burial tests in field conditions were carried out to study the degradation of the plastic bags in the natural environment. The site for the burial tests was chosen as one of the locations within the largest operating landfill sites in Kuwait (South $7^{\text {th }}$ Ring Road Landfill-29.1707 ${ }^{\circ}$ latitude and $47.9085^{\circ}$ longitude) where no presumed landfilling is to be conducted for the next two years [21]. The site also reflects the type of land used for recent waste management activities within the state as discussed with Kuwait Municipality (KM) which is responsible for such matters. Readers are referred to Figure S3 for a pictorial depiction of the procedure and the burial site. The soil properties and characteristics were previously shown in Al-Salem et al. [33]. Ten film samples were buried at a depth of $0.3 \mathrm{~m}$, so as to allow microorganism attack in accordance with the procedure of Muthukumar et al. [34]. Samples were buried for a total of 30 days. The average water absorption $\left(W_{\mathrm{abs}}, \%\right)$ and sample weight 
loss $\left(W_{\text {loss }}, \%\right)$ were estimated for the test specimens as per the following [35]:

$$
\begin{aligned}
& W_{\mathrm{abs}}(\%)=\frac{\left(W_{t}-W_{\mathrm{d}}\right)}{W_{0}} \times 100, \\
& W_{\text {loss }}(\%)=\frac{\left(W_{0}-W_{\mathrm{d}}\right)}{W_{0}} \times 100,
\end{aligned}
$$

where $W_{\mathrm{abs}}$ is the average water absorption (\%), $W_{t}$ is the remaining mass at time $t, W_{\mathrm{d}}$ is the mass of the dried sample, $W_{0}$ is the initial mass, and $W_{\text {loss }}$ is the sample weight loss (\%). Samples were removed from the soil at a specific interval $(t)$ which is taken as 30 days in this work. The samples were carefully cleansed with distilled water and superficially dried. Samples were then dried under vacuum at $35^{\circ} \mathrm{C}$ until constant weight. Samples were washed, dried, and stored in a dark laboratory space at $23^{\circ} \mathrm{C} / 50 \%$ relative humidity $(\mathrm{RH})$ between the sample collection time and characterization. Accelerated (artificial) indoor weathering (ageing) tests are commonly used for studying material integrity and were conducted in this work to determine the photodegradation extent of the studied film samples. The specimens were also exposed to accelerated weathering (AW) in accordance with ASTM D 4329 [36]. Samples were mounted on the racks facing the ultraviolet (UV) lamps with no empty spaces in the panels. This is in order to maintain uniform repeatable test conditions. The cycle A procedure was used for general application durability testing (i.e., 8 hours of UV exposure at $60^{\circ} \mathrm{C}$ followed by 4 hours of condensation at $50^{\circ} \mathrm{C}$ ). At the end of each continuous weathering test, the chamber was cooled to room temperature and the trays were set to rest on a flat surface for a minimum of 24 hours. Samples were laid to rest for a minimum of 72 hours before characterization following internationally recognised methodologies and laboratory testing protocols of weathering $[8,9,36]$. A minimum of four replicates were exposed to the different exposure durations in the QUV machine chamber. Ultraviolet (UV) lamp irradiance was also selected according to ASTM D 4329 [36], and the lamp type was set to be $0.68 \mathrm{~W} \mathrm{~m}^{-2}$ (irradiance) for normal lamp operation, which was maintained for almost 5000 hours of operation. The irradiance sensor was calibrated every 400 hours of lamp operation during the UV cycle under normal test temperature. The equipment used was cleaned every 800 hours to remove scale deposits resulting from water evaporation during the condensation cycles $[8,9]$.

\section{Results and Discussion}

3.1. Product Identification and Biodegradation (Mechanism) Route. At the first stage, the three studied products were assessed for their type and additive content. The IR spectra obtained for the three types of plastic bags were used to identify the base polymer material (Figure S4). A comparative spectrum for the reference material is also presented with the other three types of materials studied. It was noted that the spectra show a PO polymer (e.g., PE) signature [37]. This was based on the presence of the bands in the region of $2916 \mathrm{~cm}^{-1}, 2849 \mathrm{~cm}^{-1}, 1472 \mathrm{~cm}^{-1}$ and the range of 731 and $791 \mathrm{~cm}^{-1}$. These bands indicate functional groups associated with $\mathrm{C}-\mathrm{H}$ stretching asymmetric and symmetric vibrations, $\mathrm{CH}_{2}$ scissoring vibrations, and $\mathrm{CH}_{2}$ rocking vibrations, respectively [16]. These signature bands were also noted and recognised by other researchers in the past as signatory reference bands for PE polymers [38-40]. Additional peaks were also detected in the studied samples, between the $850 \mathrm{~cm}^{-1}$ and $1450 \mathrm{~cm}^{-1}$ region of each IR spectrum (Figure S4). The presence of the peaks is an indication of possible additives in the bags' formulation. Samples of the type II material showed some peak differences when compared with the other two materials. No additional peaks were evident at the $1450 \mathrm{~cm}^{-1}$ region, and the peak at $850 \mathrm{~cm}^{-1}$ was significantly less intense when compared with the other sample bags. This indicates that the formulation of this bag type is different.

Prodegradants are typically mixed with a base PO polymer to compound a biodegradable plastic product. This is in order to accelerate the degradation process. These additives will accelerate the polymer's oxidative degradation. Most common additives used for such products are stearate (St) complexes of transition metals such as zinc ( $\mathrm{ZnSt}$, copper (CuSt), silver (AgSt), cobalt (CoSt), nickel (NiSt), manganese ( $\mathrm{MnSt})$, chromium (CrSt), and vanadium (VSt) or alkaline earth metals such as magnesium (MgSt) and calcium (CaSt) [41]. The subtraction of the base polymer spectra obtained for the materials studied revealed that peaks correspond to calcium carbonate $\left(\mathrm{CaCO}_{3}\right)$, matching the regions between $2800 \mathrm{~cm}^{-1}$ and $3000 \mathrm{~cm}^{-1}$ and $1200 \mathrm{~cm}^{-1}$ to $1500 \mathrm{~cm}^{-1}$. This indicates that the studied blends are of oxo-biodegradable type.

The three types of bags along with the reference PE were also examined for their heat flow properties using DSC analysis. The main thermogram properties are depicted in Figure S5. Two indicative melting points were noted with the heat flow analysis at around $110-113^{\circ} \mathrm{C}$ and $122-130^{\circ} \mathrm{C}$, respectively, for type $\mathrm{I}$ of the samples studied. This indicates that the samples are of a commercial grade blend of polymers originating from PO materials. The melting points and thermogram properties indicate that samples of type I can be a blend of PE polymers and more precisely LLDPE and LDPE (Figure S5). This blend is a common practice with plastic compounders allowing better flow properties for thin polymeric films, which was reported previously in past investigations [9].

There was a noted melting peak between 125 and $129^{\circ} \mathrm{C}$ for type II of the studied samples with a collective area under the curve estimated at $120 \mathrm{Jg}^{-1}$ (Figure S5). Type III showed a melting point at $131^{\circ} \mathrm{C}$. The base $\mathrm{PO}$ polymer of both types is consistent with HDPE. The crystallinity measurements depicted at later stages of this communication also confirms these findings.

3.2. Evolved Gas Analysis and Metal Content. The GramSchmidt curve for the qualitative analysis of the evolved gases is presented in Figure S6. According to the Gram-Schmidt graphs for type I and type III bags, the decomposition took 
TABLE 2: Trace metal analysis for the oxo-biodegradable bags tested.

\begin{tabular}{|c|c|c|c|c|c|}
\hline Element concentration $\left(\mathrm{mg} \mathrm{kg}^{-1}\right)$ & Type I & Type II & Type III & Reference PE & $\mathrm{EC} / 94 / 62[44]$ \\
\hline Barium $(\mathrm{Ba})$ & 542 & 110 & 0.36 & 1.12 & - \\
\hline Calcium $(\mathrm{Ca})$ & 6,616 & 58,598 & 61,004 & 66,594 & - \\
\hline Cadmium $(\mathrm{Cd})$ & 0.06 & 0.14 & 0.14 & 0.42 & 100 \\
\hline Chromium (Cr) & 0.48 & 876 & 0.83 & 2.91 & 100 \\
\hline Copper $(\mathrm{Cu})$ & 194 & 0.25 & 15.7 & 12.0 & - \\
\hline Iron $(\mathrm{Fe})$ & 17.3 & 82 & 17.2 & 141 & - \\
\hline Mercury (Hg) & 0.28 & 0.27 & 0.28 & 0.31 & - \\
\hline Magnesium (Mg) & 439 & 251 & 221 & 1,117 & - \\
\hline Manganese (Mn) & 29.2 & 13.6 & 4.39 & 7.33 & - \\
\hline Nickel (Ni) & 0.48 & 1.33 & 0.47 & 1.64 & - \\
\hline Lead $(\mathrm{Pb})$ & 0.64 & 3,584 & 0.63 & 0.70 & 100 \\
\hline Sulphur (S) & 322 & 150 & 48 & 75 & - \\
\hline Antimony (Sb) & 1.00 & 0.98 & 0.99 & 1.09 & - \\
\hline $\operatorname{Tin}(\mathrm{Sn})$ & 5.63 & 5.48 & 5.53 & 6.13 & - \\
\hline Titanium (Ti) & 37.2 & 4.43 & 147 & 18.9 & - \\
\hline Vanadium (V) & 0.040 & 0.039 & 0.040 & 0.044 & - \\
\hline Zinc $(\mathrm{Zn})$ & 324 & 62 & 212 & 221 & - \\
\hline
\end{tabular}

Note to reader: boldface indicates the highest concentration in the studied sample population. The italicized reference concentration is shown when it exceeds the tested population permissible limit.

place in two steps. The first was mainly for the organic part whilst the second was for the $\mathrm{CaCO}_{3}$ (Figure S7). Type II samples showed one main decomposition peak at the organic loss region. The inorganic decomposition region was very small corresponding to the weight loss region (1.78wt.\%). From the analysis of the results, it became apparent that the type II samples showed different decomposition characteristics than the reference $\mathrm{PE}$ material. The weight loss at the organic region was $96 \%$ with no residue at $900^{\circ} \mathrm{C}$ (Figure S7). Type II also showed less weight loss at the $\mathrm{CaCO}_{3}$ region. By combining the analysis of the results, it can be noted that the samples contained $9.53 \%, 1.78 \%$, and $11.89 \%$ of $\mathrm{CaCO}_{3}$ (inorganic content/additives) for types I, II, and III, respectively. This is also consistent with the weak traces of the IR signal compiled in Figure S8 for the three tested bags and past investigations depicting oxo-biodegradable bags [42]. IR spectra for the second decomposition step were similar for types I and III and the reference material. It was consistent with a $\mathrm{CO}_{2}$ by-product of the decomposition of calcium oxide or calcium carbonate (Figure S9). Type II showed weak traces of $\mathrm{CO}_{2}$ and stronger traces of water. This could be attributed to the amount of inorganic content used in compounding the biodegradable bag. This was also noted previously in past findings on commercial-grade oxobiodegradable plastics $[17,18]$.

The total ion chromatographs (TIC) obtained from the GC/MS tests showed similar traces and were consistent with the traces from a standard PE sample (Figure S10). However, it should be noted that type II showed weaker traces compared with the rest of the samples. This could be attributed to the less amount of additives present in the formulation and the distribution of the alkane/carbon numbers in the PO base polymer [43]. A total metal content analysis was performed for the three tested materials and the reference plastic bag. Inductive couple plasma optical emission spectroscopy technique was conducted, and the results are shown in Table 2. All samples showed high levels of calcium (Ca) which is a standard filler in PE oxo-biodegradable bags. In addition, the bag samples also showed high traces of heavy metals which is a common practice for the UK market where the reference bag is secured from. Typically, heavy metals are used to promote fragmentation and biodegradability [7]. Also, powder form $\mathrm{Ca}$ and $\mathrm{Zn}$ stearates are widely used in the plastic industry as lubricants and heat stabilizers.

By comparison to the reference PE specimen, type I of the tested material revealed high levels of $\mathrm{Ba}, \mathrm{Cu}, \mathrm{Mg}, \mathrm{S}$, and $\mathrm{Zn}$ (Table 2). The ICP tests revealed high levels of $\mathrm{Ba}, \mathrm{Cu}, \mathrm{Mg}, \mathrm{S}$, and $\mathrm{Zn}$. Majority of the detected metals could be associated with the biodegradable characteristic of the bag. No significant levels of these elements were found in the reference PE bag apart from magnesium. In addition, the metal screening analysis revealed that type II samples contained extremely high levels of $\mathrm{Pb}$ and high levels of $\mathrm{Ba}$ and $\mathrm{Cr}$. These elements were not witnessed in the reference PE specimens and therefore could be associated with the biodegradable additives in type II bags. However, it should be stressed that both $\mathrm{Pb}$ and $\mathrm{Cr}$ are regulated elements in the use of plastic products for packaging. According to 94/62/EC regulation for packaging materials, the limit of $\mathrm{Pb}$ and chromium is $60 \mathrm{ppm}$. Herein, the levels of lead were 60 times above the limit and the level of chromium was 15 times above the permissible limit. ICP testing did not show any high levels of standard metals compared with the other samples. It should be highlighted that the levels of $\mathrm{Cr}$ and $\mathrm{Pb}$ found in 
TABLE 3: Water absorption (\%) and weight loss (\%) with respect to soil burial time.

\begin{tabular}{lccccc}
\hline Sample type & $W_{0}(\mathrm{~g} /$ specimen $)$ & $W_{\mathrm{t}}(\mathrm{g} /$ specimen $)$ & $W_{(\mathrm{dry})}(\mathrm{g} /$ specimen $)$ & $W_{\text {abs }}(\%)$ & $W_{\text {loss }}(\%)$ \\
\hline Type I & 0.418 & 0.140 & 0.139 & 0.191 & 66.618 \\
Type II & 0.211 & 0.087 & 0.087 & 0.094 & 58.628 \\
Type III & 0.203 & 0.089 & 0.077 & 5.905 & 62.106 \\
\hline
\end{tabular}

the type II bag are exceeding by far the maximum accepted criteria according to the European Union regulations for packaging material 94/62/EC and for food contact materials EU No. 10/2011 [44]. However, type III samples did show higher levels of Ti element which could be very well associated with the white colouring of the bag, as titanium oxide is the standard pigment for white colouring. Plastic compounders within the state should be aware to avoid contamination/migration possibility after disposal of such bags, in reducing the concentration of pigment leading to such high levels of heavy metals. Starch-based products are advisable to avoid such high level of metal contamination. Adherence to international standards specifying metal content is essential in avoiding the release of heavy metals in open environments (e.g., exposed soil matrix). The work conducted in this study suggests that convertors of claimed biodegradable plastic film products should adhere to EC standards shown previously in Table 2 . The enforcement of such standards will pave the way for future recycling plans within the Middle East (ME) region. This is in order to reduce metal content in plastics before thermal or mechanical treatment as well, which will result in a more sustainable practice in a closed recycling loop manner.

\subsection{Crystallinity and Thermal Stability Postenvironmental} Exposure. The degree of crystallinity determines the amount of the deteriorated regions in semicrystalline polymers. The materials studied in this work were exposed to both routes of degradation commonly associated with PO polymers. These are biodegradation in soil contact (Figure S3) and photodegradation using UV-induced weathering tests. The materials were buried in accordance with the described protocol previously illustrated in the previous section. The three tested samples were recovered and tested after 30 days of continuous burial in soil with characteristics described elsewhere [45]. Table 3 shows the weight loss analysis and water absorption determined after soil burial.

Water absorption estimated in this study shows that type III was the most absorbent material. This is a typical indicator of oxo-biodegradable polymers, where the plastic surface will turn to hydrophobic with burial time dependent on their thickness and prodegradant concentration [34]. By that stage, oxidation of the reminder polymeric chain will occur. Type III possesses the lowest thickness of the materials tested and the highest $\mathrm{CaCO}_{3}$ concentration $(\approx 12$ wt.\%). Starchbased components are more favourable for soil burial and can also enrich the surrounding environment by incorporating nutrients in the polymeric matrix with more ease $[35,46]$. All sample types were noted to decrease in their weight post soil testing. This could be attributed to the loss of molar mass associated with macromolecular chain bond scission
[47-49]. The molar mass of LLDPE was previously studied postexposure to natural weathering [25]. The variation and changes in the mass of the polymer were attributed to the thickness of the samples and amount of additives.

Type I of the sample studied was noted to have the highest loss of weight $(\approx 66 \%)$ in comparison to the other tested materials. Type I is also the thickest sample type dealt with in this work, where the sample weight was observed to be rapidly lost due to the concentration of the biodegradable prodegradant present in them. This confirms the action of biodegradation of the samples under microorganism attack within soil contact (Table 3). The ion complexes and metals present in oxo-biodegradables start to decompose the hydroperoxides produced during the polymer oxidation process. At the first stage, oxo-degradation additives will promote abiotic (photo or thermo)oxidation. The second stage of decomposition will be microbial biodegradation [50]. At these stages, the hydrophobic nature of the polymer will be irrelevant and redundant since humidity will start to play a major factor in the degradation rate. Oxidized PE releases low MW compounds in aqueous media which could be consumed by microorganisms [7]. Potentially, these compounds could be harmful to surrounding environments. In a past study, the Rhodococcus rhodochrous strain consumed low MW compounds in water media from oxidized HDPE and LDPE after four days of cultivation [51]. These compounds could be up to twelve carbons in length [52]. The decreasing order of PE susceptibility to degradation in soil mixed with refuse was previously established as LLDPE $>$ LDPE $>$ HDPE [2]. The work in this study shows that oxo-biodegradables are closely related to concentration of prodegradants and type of PE polymer.

The samples tested in this work were also exposed to the action of accelerated weathering. This is in order to determine their photodegradation behaviour with respect to various exposure times. The threshold limit (e.g., point of total deterioration) was determined and discussed elsewhere [21]. The materials in this work were exposed to three different times spans to study the degradation profile with respect to exposure time. The materials were exposed to the threshold limits which were 11,13 , and 19 days of continuous weathering, for types I, II, and III, respectively. Samples were also exposed to $1 / 3$ and $2 / 3$ of the total exposure duration (Table S1). The equivalence general timeline for PO polymers exposure in Kuwait was previously estimated as 1 hour (in accelerated weathering) to 1 day in natural (outdoor) weathering [9]. Table S2 shows the degree of crystallinity estimated for the tested materials before and after the soil burial test. Table S3 also shows the crystallinity of the materials after performing the accelerated weathering test. 


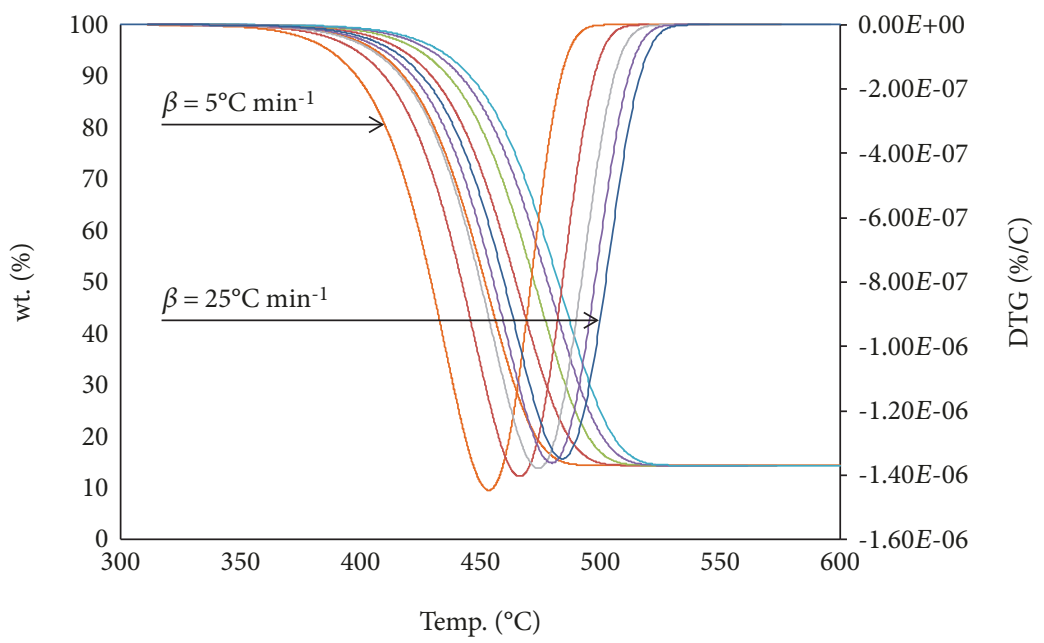

FIGURE 2: TGA thermogram showing weight loss and first derivative of type I sample pre-exposure with respect to heating rates (5 to $25^{\circ} \mathrm{C} \min ^{-1}$ ) in sequential order (left to right).

The crystallinity estimated post the soil burial tests showed an increase in all studied samples. The crystallinity values estimated from the control specimens are depicted in Table S2. The largest increase was estimated for type II which could be due to the fact that it encompasses a different formulation to the other two materials (Table S2). The increase in crystallinity points towards the loss of the amorphous region in the material due to the occurring degradation. The deterioration was also evident in the thermograms inspected post soil burial tests which show a shift in the melting point curve associated with the heating loop (Figure S5). In the case of accelerated weathering, samples showed a general decreasing trend towards the threshold limit with the exception of type III (Table S3). For type I, the first 88 hours revealed that the crystallinity is at its lowest value estimated from both heating cycles. Type II showed a similar behaviour, and both types I and II showed a slight increase in crystallinity towards the threshold limit. The values of the threshold limit crystallinity were lower than the original crystallinity values of the materials tested.

On the other hand, type III showed an increasing trend with respect to exposure time. The structure of $\mathrm{PE}$ allows rapid photodegradation with weathering due to the high degree of permeability to oxygen molecules [53]. The average glass transition temperature $\left(T_{\mathrm{g}}\right)$ reported for $\mathrm{PE}$ is $-70^{\circ} \mathrm{C}$, which is below the UV exposure and condensation temperatures used in this work for weathering tests. This facilitates the rearrangement of the crystalline phase due to the mobility of the amorphous region [54]. This can explain the reason behind the increase in crystallinity towards the threshold limit of weathering time for type III of the samples examined. This points towards rapid degradation of type III of the samples. However, types I and II showed rapid decrease in crystallinity which can be attributed to the increase in the evolution of chemicals from the termination reaction in the photodegradation mechanism of PE [44]. Ojeda et al. [25] also attributed the increase in crystallinity to the decrease in molecular size.
TGA data has been extensively used in the past to study the thermal stability of various polymers. Weight loss determination is crucial to studying the extent and type of the governing mechanism of polymer decomposition. The smoothened TGA curves are depicted in Figures 2-4 following Al-Salem and Khan's [55] approach to focus on the extent of PE degradation. Table 4 shows the main thermal properties deduced from the TGA thermograms including the onset temperature ( $T_{\mathrm{os}}$, measured at $5 \mathrm{wt} \%$ loss), midset temperature $\left(T_{\mathrm{ms}}\right)$, maximum degradation temperature ( $T_{\max }$, measured at initial temperature with maximum weight loss), and inflection point $\left(T_{\text {if }}\right)$ [45].

Values of the $T_{\text {os }}$ were noted to be very similar between the three studied types of plastic products. This was expected since all were previously confirmed to be of PE polymer origin. The investigated blends followed past reports of thermal properties shown in previously published research on PE polymers [56-59]. The thermal properties were irrelevant to content of $\mathrm{CaCO}_{3}$ and showed similarities with virgin commercial-grade PE resin. The other thermal properties were noted to be of similar nature between the three types (Table 4). The inflection point has shown a consecutive change with the value of $\beta$ which is a result of the change in thermal mechanism and response expected with PO polymers. Thickness of the material was noted to be irrelevant on the studied properties. A clear change in the degradation curve was observed with the consecutive displacement of the curves shown in Figures 2-4 [60]. The samples exposed to the soil burial test and exposed to the threshold limit of accelerated weathering were also subjected to thermogravimetric analysis (Figures S11-S16, Tables S4 and S5).

Figures S11-S16 show the experimental curves of the tested plastic materials after exposure to the threshold limit in accelerated weathering conditions and soil burial. It can be noted that all materials show only a single degradation step in the thermograms obtained for a singular polymeric material. This was expected since the base polymer is $\mathrm{PE}$ without any additional blends from other types of $\mathrm{PO}$ or polyester polymers. This indicates that the materials are 


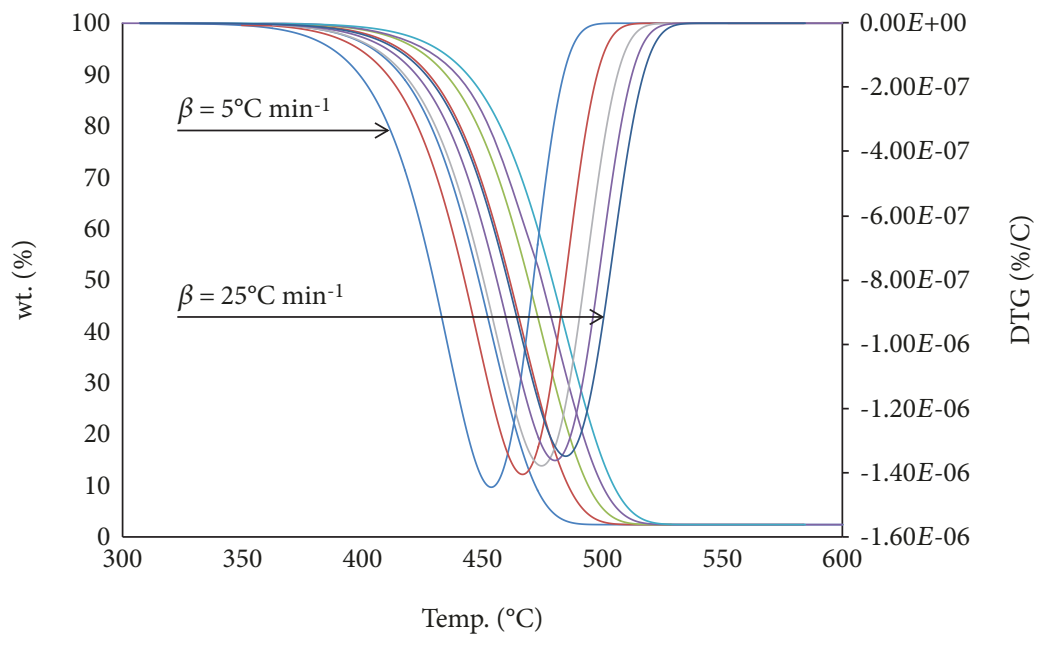

FIGURE 3: TGA thermogram showing weight loss and first derivative of type II sample pre-exposure with respect to heating rates (5 to $25^{\circ} \mathrm{C} \mathrm{min}^{-1}$ ) in sequential order (left to right).

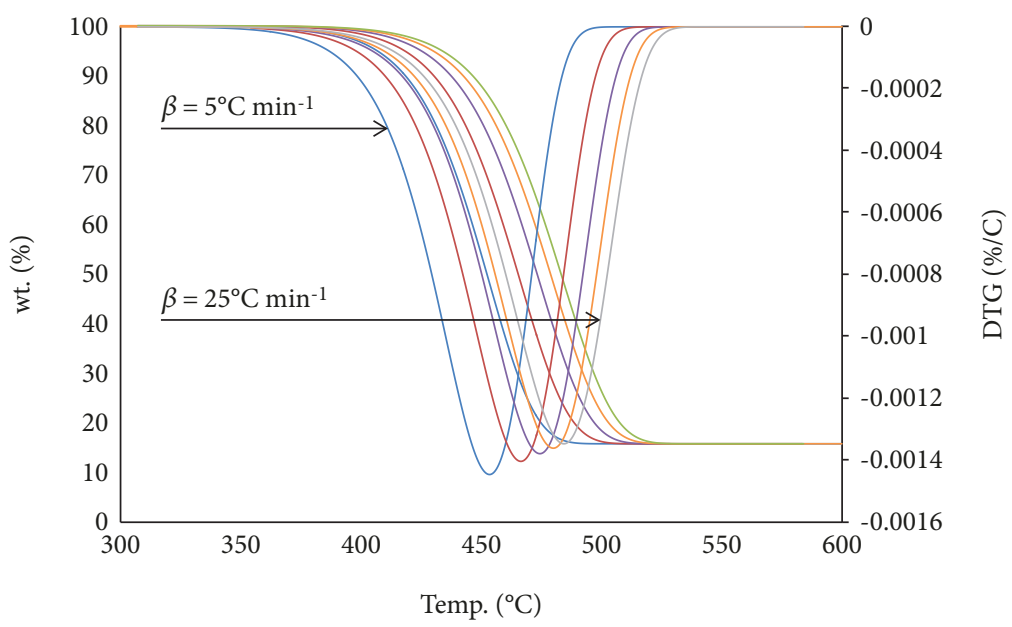

FIGURE 4: TGA thermogram showing weight loss and first derivative of type III sample pre-exposure with respect to heating rates (5 to $25^{\circ} \mathrm{C} \mathrm{min}^{-1}$ ) in sequential order (left to right).

clear of any starch-based additives, glycerins, or additional polymers (other than $\mathrm{PE}$ ). This supports the claim that the materials are of oxo-biodegradable nature.

Examining the temperature profile post accelerated weathering reveals that there was a slight shift in the thermograms with the increase in exposure duration (Table S4). This can be attributed to the impact of the UV on the material matrix. Degradation of the materials resulted in an increase in the onset temperature indicating higher energy requirement for thermal recycling. The impact of UV exposure was very similar in all types of studied materials. This could be attributed to the fact that the exposure has impacted the polymeric fraction of the plastic bag irrelevant of the presence of the inorganic filler (i.e., $\mathrm{CaCO}_{3}$ ). However, the materials were all within the same region of thermal properties and degradation profile established by other researchers for PO polymers [61-63].
Table S5 shows the degradation profile of the materials after 30 days of soil burial. The resulting profile depicts some $60^{\circ} \mathrm{C}$ shift in the $T_{\text {os }}$ between exposed and unexposed film samples. The action of biodegradation, confirmed with weight loss analysis, rapidly attacks the polymeric chains. This leaves behind longer and more brittle HC chains notable for their slow release in the environment. These HCs include the inorganic parts which show a more susceptibility to reclaim and thermally treat based on the temperature profile examined in this work. The change in the inflection and maximum degradation temperatures also confirms this analysis. This shows that oxo-biodegradable polymers are less favourable for thermochemical treatment. However, these materials are best reclaimed and treated via mechanical recycling techniques as shown in past research works $[61,63]$. The amount of inorganic prodegradant was noted to be irrelevant to the temperature ranges, as buried 
TABLE 4: Thermal stability and properties for the materials investigated (pre-exposure).

\begin{tabular}{lccccc}
\hline $\begin{array}{l}\text { Heating rate } \\
\left({ }^{\circ} \mathrm{C} \mathrm{min}{ }^{-1}\right)\end{array}$ & 5 & 10 & 15 & 20 & 25 \\
\hline $\begin{array}{l}\text { Type I } \\
T_{\text {os }}\left({ }^{\circ} \mathrm{C}\right)\end{array}$ & 406.08 & 417.33 & 424.00 & 429.00 & 432.50 \\
$T_{\text {mid }}\left({ }^{\circ} \mathrm{C}\right)$ & 451.75 & 464.50 & 472.25 & 477.66 & 482.08 \\
$T_{\max }\left({ }^{\circ} \mathrm{C}\right)$ & 509.58 & 524.50 & 533.75 & 540.33 & 545.41 \\
$T_{\text {if }}\left({ }^{\circ} \mathrm{C}\right)$ & 453.00 & 466.50 & 474.00 & 482.00 & 484.00 \\
\hline Type II & & & & & \\
$T_{\text {os }}\left({ }^{\circ} \mathrm{C}\right)$ & 406.41 & 417.66 & 424.25 & 429.00 & 432.91 \\
$T_{\operatorname{mid}}\left({ }^{\circ} \mathrm{C}\right)$ & 452.25 & 465.00 & 472.75 & 478.33 & 482.50 \\
$T_{\max }\left({ }^{\circ} \mathrm{C}\right)$ & 509.58 & 524.50 & 533.50 & 540.00 & 545.41 \\
$T_{\text {if }}\left({ }^{\circ} \mathrm{C}\right)$ & 454.00 & 467.00 & 474.75 & 482.90 & 484.58 \\
\hline Type III & & & & & \\
$T_{\text {os }}\left({ }^{\circ} \mathrm{C}\right)$ & 404.00 & 415.166 & 421.75 & 426.66 & 430.41 \\
$T_{\operatorname{mid}}\left({ }^{\circ} \mathrm{C}\right)$ & 448.167 & 460.83 & 468.50 & 474.00 & 478.33 \\
$T_{\max }\left({ }^{\circ} \mathrm{C}\right)$ & 512.50 & 527.50 & 536.75 & 543.33 & 548.33 \\
$T_{\text {if }}\left({ }^{\circ} \mathrm{C}\right)$ & 453.75 & 466.67 & 477.00 & 482.50 & 484.58 \\
\hline
\end{tabular}

samples showed similar temperature ranges regardless of the type of specimen.

3.4. Degradation Kinetics. The degradation kinetics were investigated using the thermogravimetric analysis conducted on the three studied samples. The plastic films exposed to accelerated weathering and soil burial were compared to the control samples (unexposed plastics). The aim is to estimate the apparent activation energy $\left(E_{\mathrm{a}}\right)$ using various methods to determine the changes in the degradation mechanism and the required energy to degrade the materials. To this end, the plastic material conversion was defined as $(\alpha)$ with respect to the reaction time; thus [61],

$$
\alpha=\frac{m-m_{0}}{m_{0}-m_{\mathrm{f}}},
$$

where $m$ is the mass of polymeric material at a specific time of reaction $(t)$, and $m_{0}$ and $m_{\mathrm{f}}$ are the initial and final mass of the polymer at the investigated temperature desired and final reaction time, respectively. The rate for degressive kinetics is typically defined according to the change in reaction rate by incorporating the first order for the Arrhenius equation as per the following [61, 62]:

$$
\frac{d \alpha}{d t}=A_{0} \exp \left(\frac{-E_{a}}{R T}\right) f(\alpha)
$$

where $A_{0}$ stands for the pre-exponential (or frequency) factor $\left(\mathrm{min}^{-1}\right), E_{\mathrm{a}}$ is the apparent activation energy $\left(\mathrm{kJ} \mathrm{mol}^{-1}\right), T$ is the reaction temperature at the desired time $(\mathrm{K})$, and $f(\alpha)$ is the reaction model that represents the degradation mechanism following a reaction order typically denoted as $n$.

The first method used in this work was the Friedman's isoconversion method utilizing the techniques of model- free kinetics analysis as depicted previously by various authors $[31,61,62]$. The natural logarithm of both sides of the previous equation is taken to reveal the expression used as per the following:

$$
\ln \left(\frac{\mathrm{d} \alpha}{\mathrm{d} t}\right)=\ln \left[A_{0} f(\alpha)\right]-\frac{E_{\mathrm{a}}}{R T} .
$$

This gives the assumption that a mere plot of $\ln (\mathrm{d} \alpha / \mathrm{d} t)$ versus $1 / T$ at a fixed value of conversion, taken as $5 \%$ in this work, results in a straight line with a slope of $E_{\mathrm{a}} / R$ and the apparent activation energy $\left(E_{\mathrm{a}}\right)$ is calculated from this method at each heating rate $(\beta)[31,61]$. By utilizing the multiple heating rates of the integral Kissinger method, the following expression can be used for the determination of the kinetic parameters $[31,64]$ :

$$
\ln \left(\frac{\beta}{T_{\mathrm{m}}^{2}}\right)=\frac{-E_{\mathrm{a}}}{R T_{\mathrm{m}}}-\ln \left[\frac{E}{A_{0} R} \int_{0}^{\infty} \frac{d(\alpha)}{f(\alpha)}\right],
$$

where $\beta$ is the heating rate $\left({ }^{\circ} \mathrm{C} \mathrm{min}^{-1}\right)$ and $T_{\mathrm{m}}$ is the maximum degradation temperature. A plot of $\ln \left(\beta / T_{\mathrm{m}}^{2}\right)$ vs. $1 / T_{\mathrm{m}}$ makes it possible to determine the value of $E_{\mathrm{a}}$ for each polymer or blend [63]. The isoconversional kinetics of the Flynn-Wall-Ozawa (FWO) method was also applied in this work to estimate the $E_{\mathrm{a}}$ values described previously by Aboulkas et al. [64].

$$
\ln (\beta)=\ln \left[\frac{A E_{\mathrm{a}}}{g(\alpha) R}\right]-5.331-1.052\left(\frac{E_{\mathrm{a}}}{R T}\right) .
$$

A linear relationship is obtained by plotting $\ln (\beta)$ vs. $1 / T$ at an interval of $5 \%$ polymer conversion, and $E_{\mathrm{a}}$ is obtained from the straight line's slope. Readers are referred to Vyazovkin et al. $[26,27]$ and Al-Salem et al. [61] for a depiction of the $g(\alpha)$ and $f(\alpha)$ expression used in kinetics computation. Readers are also referred to Al-Salem et al. [61, 62] where the same methodology was applied for other PO polymers. Figure 5 shows a sample of the $E_{\mathrm{a}}$ determination plot of type I using Friedman's method.

The conversion rate $(\alpha)$ varied considerably between the studied samples. $\alpha$ was estimated to be at a maximum rate for types I, II, and III as $85 \%, 95 \%$, and $90 \%$, respectively. The conversion was dependent on the amount of residual char in the TGA crucible and the inorganic prodegradant concentration in each material. Exposure to the threshold limit in accelerated weathering showed a clear impact on the linearity of Friedman's plot. A shift with a higher conversion rate was apparent, indicating a change in the degradation mechanism. This could be attributed to the cross-linking reaction towards the termination of the photodegradation mechanism for PE [62]. A similar effect was also noted with material exposed to soil burial for 30 days. In addition, a more shift towards higher $\alpha$ values was noted. This could be due to the microorganisms' degressive action on the polymeric chains. Figure 6 shows the Kissinger plots for the materials considered in this work. 


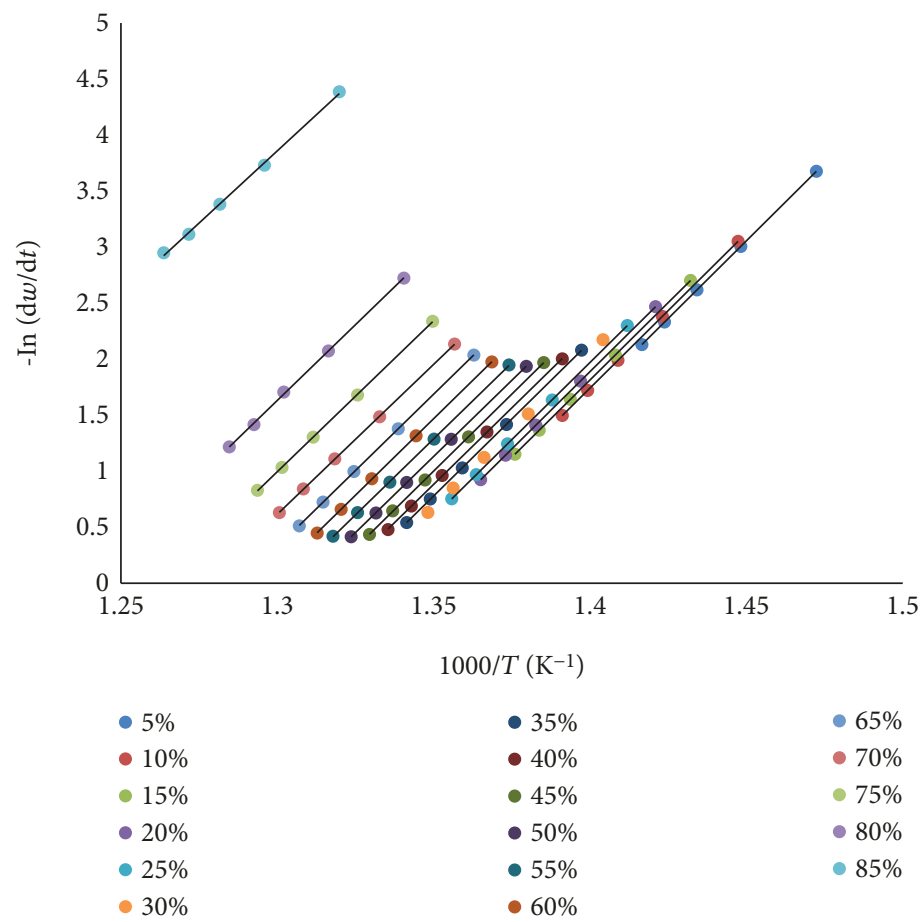

FIGURE 5: Determination of apparent activation energy $\left(E_{\mathrm{a}}\right)$ using Friedman's isoconversion method for type I (pre-exposure).

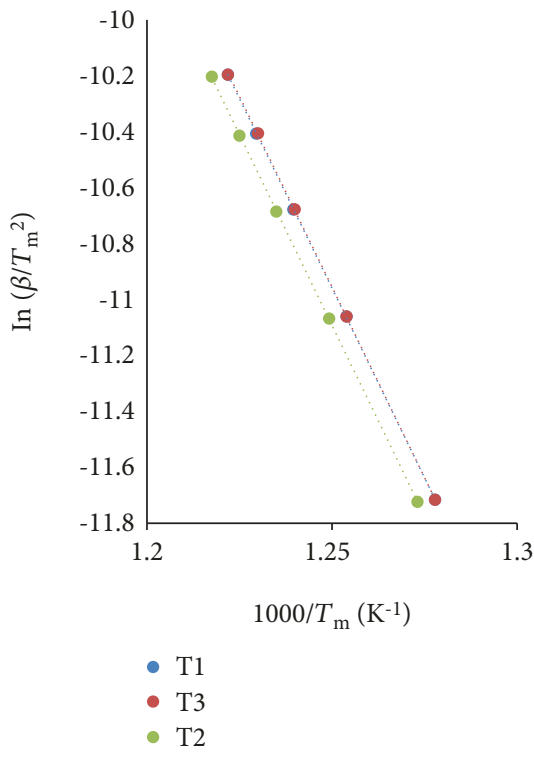

(a)

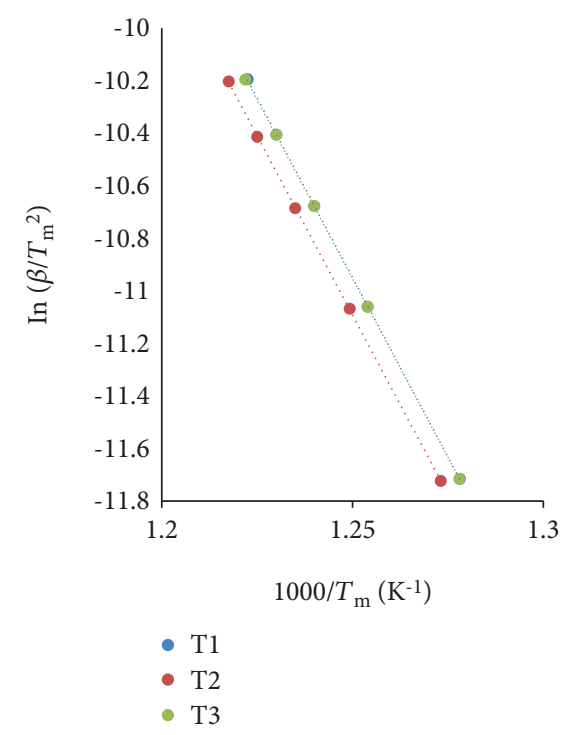

(b)

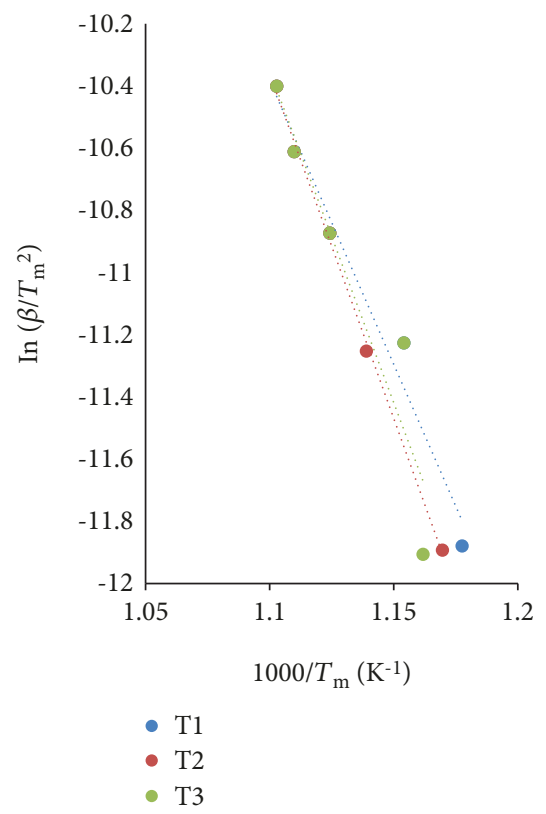

(c)

FIGURE 6: Determination of apparent activation energy $\left(E_{\mathrm{a}}\right)$ using Kissinger's method for (a) pre-exposed samples, (b) accelerated weathering, and (c) soil burial.

A similar conversion rate was noticed between both types I and III regardless of the exposure media (Figure 6). This could be a result in the similarity between both materials' types and conversion rates. All samples exhibited high linearity indicating that the method was applicable for degressive conditions studied in this work. The FWO method also showed high regression coefficients and linearity amongst the studied sample population, and Table 5 summarises the $E_{\mathrm{a}}$ values obtained in this work.

PE will typically degrade in a range of $E_{\mathrm{a}}$ between 102 and $347 \mathrm{~kJ} \mathrm{~mol}^{-1}$ [58]. Results will typically be dependent on the selected method, type of material, experimental conditions, and accuracy of measurements [59]. In this work, the FWO method resulted in the lowest $E_{\mathrm{a}}$ values (Table 5). FWO relies 
TABLE 5: Summary of apparent activation energy $\left(E_{\mathrm{a}}, \mathrm{kJ} \mathrm{mol}^{-1}\right)$ values estimated from the various methods in this work.

\begin{tabular}{lccc}
\hline Methods & Type I & Type II & Type III \\
\hline Pre-exposure & & & \\
Friedman & 225.30 & 225.60 & 224.69 \\
Kissinger & 225.36 & 226.90 & 226.51 \\
Flynn-Wall-Ozawa & 103.75 & 103.77 & 103.83 \\
\hline Accelerated weathering & & & \\
Friedman & 225.21 & 225.39 & 224.07 \\
Kissinger & 227.15 & 226.90 & 225.96 \\
Flynn-Wall-Ozawa & 103.89 & 103.70 & 103.77 \\
\hline Soil burial & & & \\
Friedman & 184.68 & 185.57 & 171.63 \\
Kissinger & 151.95 & 184.18 & 177.68 \\
Flynn-Wall-Ozawa & 86.64 & 89.38 & 86.97 \\
\hline
\end{tabular}

on the conversion rate with respect to each $\beta$ value. It is typically used as a first indicator to the number of stage in the mechanism of degradation and the general values resulting from the pyrolytic reaction of $\mathrm{PO}$ degradation. In this work, the FWO resulted in values for type III lower than those of types I and II for all exposure conditions. This was expected since the conversion rate for the unexposed and exposed samples of type III were lower than the other materials. The Kissinger method showed temperature-dependent values of $E_{\mathrm{a}}$ which noted to be in the range of past investigations $[58,59,61]$. The same was noted for Friedman's method. The materials exposed to soil burial tests resulted in $E_{\mathrm{a}}$ values lower than those exposed to the accelerated weathering ones. This could be attributed to the weight of the samples post soil burial tests, higher rates of conversion, and the cross-linking of the polymeric chain resulting towards the 30-day period of the soil burial. Materials subjected to thermochemical treatment that are of oxo-biodegradable nature can be treated in mechanical recycling schemes as previously shown in past work [64]. The shift in the thermograms previously discussed in this communication shows that more energyintense operations are required for thermal treatment of such materials. Energy optimization solutions are recommended to overcome this obstacle especially given that the overall $E_{\mathrm{a}}$ seems to reduce with exposure to environmental conditions. Therefore, it might be worth for future recycling plans to incorporate such materials as a feedstock for thermal units since the overall required energy seems to be decreasing with exposure. Therefore, reclaimed PSW could be treated with ease in such cases within the near future despite the increase in energy and utility requirements for unit operation start-ups. These schemes could also be complemented by chemical recycling plants focusing on other types of polymeric materials, such as polyamides, via hydrolysis or glycolysis [5]. In doing so, a closedloop recycling plan can be developed for the country as a whole whilst mitigating associated environmental burdens of PSW accumulation.

\section{Conclusions}

In an effort to manage plastic waste accumulation and pollution, various societies are undertaking serious measures in introducing biodegradable plastic products to local markets. In this work, three commercially available plastic film products used within the state of Kuwait (and claimed to be biodegradable) were studied for their suitability under local environmental conditions and thermal response. Standard plastic specimens of the three products were subjected to a series of characterization techniques to reveal both the type of the plastic product and the prodegradant material used as a filler. Three products were locally used as plastic film products for packaging, waste, and carrier bag applications. It was revealed that types I and III contained about 10 wt.\% of $\mathrm{CaCO}_{3}$ as an inorganic prodegradant, whilst type II contained $1.7 \mathrm{wt} . \%$ of the same material. The heat flow analysis also revealed that type I was a blend of LLDPE/ LDPE. Furthermore, types II and III had HDPE as a base polymer. The mechanism of degradation of the specimens was also consistent with oxo-biodegradables in soil media. On the other hand, plastic film products of such nature compounded with similar properties must be regulated to a better standard in Kuwait. The heavy metal analysis conducted on the samples from type II showed that the films possessed lead $\mathrm{Pb}$ ) content above the acceptable range of safe plastic use for commercial products. High levels of barium (Ba), copper $(\mathrm{Cu})$, magnesium $(\mathrm{Mg})$, sulphur $(\mathrm{S})$, and zinc $(\mathrm{Zn})$ were also noted amongst the samples studied in this work due to the high level of pigmentation. The materials studied were also subjected to thermogravimetric analysis coupled with a kinetics investigation. It was revealed that exposure to accelerated weathering and soil burial shifted the thermal degradation profile for $60^{\circ} \mathrm{C}$. This increase shows a higher demand for energy input and utility requirements for potential treatment of such reclaimed materials in thermal recycling unit. However, the overall apparent activation energy $\left(E_{\mathrm{a}}\right)$ of the degradation reactions estimated from various analytical methods shows that reclaimed oxobiodegradables can be treated with less energy-intense operation. This shows the potential for treating plastic products reclaimed from landfill sites and waste streams with an optimized energy framework that can provide high energy input at start-up operations whilst recovering valuable chemicals and products towards the end of stream in unit processes. The isoconversion method of Friedman has also revealed a shift in the degradation mechanism towards higher conversion rates. This can be attributed to the degree of degradation, cross-linking, and rate of conversion of the materials with respect to each exposure condition. This work can also be used as a guideline for future reference regarding standards development for the state of Kuwait in managing plastic products.

\section{Abbreviations}

$\mathrm{E}_{\mathrm{a}}: \quad$ Apparent activation energy $\left(\mathrm{kJ} \mathrm{mol}^{-1}\right)$.

FTIR: Fourier transform infrared spectrometry

HC: Hydrocarbon 
HDPE: High-density polyethylene

ICP-MS: Inductively coupled plasma mass spectrometry

IR: Infrared

LDPE: Low-density polyethylene

LLDPE: Linear low-density polyethylene

MSW: Municipal solid waste

MW: Molecular weight

PO: $\quad$ Polyolefin

PP: $\quad$ Polypropylene

PSW: $\quad$ Plastic solid waste

SW: $\quad$ Solid waste

TIC: Total ion chromatographs

$T_{\text {max }}: \quad$ Maximum degradation temperature $\left({ }^{\circ} \mathrm{C}\right)$

$T_{\mathrm{ms}}: \quad$ Mid-set temperature $\left({ }^{\circ} \mathrm{C}\right)$

$T_{\text {os: }}$ : Onset temperature $\left({ }^{\circ} \mathrm{C}\right)$

USEPA: United States Environmental Protection Agency

$W_{\text {abs }}: \quad$ Absolute weight (\%)

$W_{\text {loss: }}: \quad$ Sample weight loss (g)

$W_{0}$ : $\quad$ Initial mass $(\mathrm{g})$.

\section{Data Availability}

The data used to support the findings of this study are available from the corresponding author upon request and client's approval.

\section{Conflicts of Interest}

The authors declare no conflict of interest.

\section{Acknowledgments}

The principal author would like to thank the Kuwait Institute for Scientific Research (KISR) for funding and supporting this research project under the grant for Project EM097C. The principal author would also like to thank Kuwait Municipality (KM) for funding and supporting this research project. The continuous support and encouragement of the management of the Environment Affairs Department of Kuwait Municipality (KM) is highly appreciated.

\section{Supplementary Materials}

The following supplementary data files are available for the readers' consideration and are referenced within the body of text. Figure S1: standard specimen size used (film dimensions: $20 \times 1 \mathrm{~cm}$ ). Figure S2: TG-IR apparatus for evolved gas analysis. Figure S3: pictorial depiction of the soil burial site used in this work. Figure S4: FTIR spectra obtained for the three analysed plastic bags with the reference nondegradable PE bag showing in sequential order from top to bottom, type II, type I, type III, and reference PE bag. Figure S5: DSC thermograms of all three sample bags showing the 2nd heat cycle along with the basic thermal properties. Figure S6: Gram-Schmidt graphs for the tested samples along with the reference PE material. Figure S7: TGA experimental thermograms obtained from the three sample types and the reference PE sample. Figure S8: IR spectra for the evolved gases showing both decomposition steps. Figure S9: IR spectra for the evolved gases showing the second decomposition stage. Figure S10: total ion chromatographs of all samples including PE reference sample (virgin) and PE reference bag. Figure S11: thermogravimetric analysis (TGA) curve showing wt.(\%) and first derivative curve (DTG) with respect to temperature $\left({ }^{\circ} \mathrm{C}\right)$ for type I post threshold limit accelerated weathering test. Figure S12: thermogravimetric analysis (TGA) curve showing wt.(\%) and first derivative curve (DTG) with respect to temperature $\left({ }^{\circ} \mathrm{C}\right)$ for type II post threshold limit accelerated weathering test. Figure S13: thermogravimetric analysis (TGA) curve showing wt.(\%) and first derivative curve (DTG) with respect to temperature $\left({ }^{\circ} \mathrm{C}\right)$ for type III post threshold limit accelerated weathering test. Figure S14: thermogravimetric analysis (TGA) curve showing wt.(\%) and first derivative curve (DTG) with respect to temperature $\left({ }^{\circ} \mathrm{C}\right)$ for type I post 30 days of soil burial. Figure S15: thermogravimetric analysis (TGA) curve showing wt.(\%) and first derivative curve (DTG) with respect to temperature $\left({ }^{\circ} \mathrm{C}\right)$ for type II post 30 days of soil burial. Figure S16: thermogravimetric analysis (TGA) curve showing wt.(\%) and first derivative curve (DTG) with respect to temperature $\left({ }^{\circ} \mathrm{C}\right)$ for type III post 30 days of soil burial. Table S1: threshold limit of tested materials determined using accelerated weathering means. Table S2: crystallinity (\%) estimated from second heating cycles for the soil burial samples. Table S3: crystallinity (\%) estimated from second heating cycles for the accelerated weathering samples. Table S4: thermal stability and properties for the materials investigated (accelerated weathering TL). Table S5: thermal stability and properties for the materials investigated (soil burial30 days). (Supplementary Materials)

\section{References}

[1] J. Arutchelvi, M. Sudhakar, A. Arkatkar, M. Doble, S. Bhaduri, and P. V. Uppara, "Biodegradation of polyethylene and polypropylene," Indian Journal of Biotechnology, vol. 7, pp. 9-22, 2008.

[2] Y. Zheng, E. K. Yanful, and A. S. Bassi, "A review of plastic waste biodegradation," Critical Reviews in Biotechnology, vol. 25, no. 4, pp. 243-250, 2005.

[3] A. F. Al-Yaqout and M. F. Hamoda, "Evaluation of landfill leachate in arid climate - a case study," Environment International, vol. 29, no. 5, pp. 593-600, 2003.

[4] D. Lithner, A. Larsson, and G. Dave, "Environmental and health hazard ranking and assessment of plastic polymers based on chemical composition," Science of The Total Environment, vol. 409, no. 18, pp. 3309-3324, 2011.

[5] S. M. Al-Salem, P. Lettieri, and J. Baeyens, "Recycling and recovery routes of plastic solid waste (PSW): a review," Waste Management, vol. 29, no. 10, pp. 2625-2643, 2009.

[6] J. M. Morancho, X. Ramis, X. Fernandez et al., "Calorimetric and thermogravimetric studies of UV-irradiated polypropylene/starch-based materials aged in soil," Polymer Degradation and Stability, vol. 91, no. 1, pp. 44-51, 2006.

[7] M. Koutny, J. Lemaire, and A. M. Delort, "Biodegradation of polyethylene films with prooxidant additives," Chemosphere, vol. 64, no. 8, pp. 1243-1252, 2006.

[8] S. M. Al-Salem, "Influence of natural and accelerated weathering on various formulations of linear low density polyethylene 
(LLDPE) films," Materials \& Design, vol. 30, no. 5, pp. 17291736, 2009.

[9] S. M. Al-Salem, G. Abraham, O. A. Al-Qabandi, and A. M. Dashti, "Investigating the effect of accelerated weathering on the mechanical and physical properties of high content plastic solid waste (PSW) blends with virgin linear low density polyethylene (LLDPE)," Polymer Testing, vol. 46, pp. 116-121, 2015.

[10] S. Bonhomme, A. Cuer, A. M. Delort, J. Lemaire, M. Sancelme, and G. Scott, "Environmental biodegradation of polyethylene," Polymer Degradation and Stability, vol. 81, no. 3, pp. 441452, 2003.

[11] B. Messenger, "Interactive map - world's most wasteful countries, Waste Management World," July 2018, https:// waste-management-world.com/a/interactive-map-worlds-mostwasteful-countries.

[12] S. M. Al-Salem, "Influential parameters on natural weathering under harsh climatic conditions of mechanically recycled plastic film specimens," Journal of Environmental Management, vol. 230, pp. 355-365, 2019.

[13] F. Markowicz, G. Król, and A. Szymańska-Pulikowska, "Biodegradable package-innovative purpose or source of the problem," Journal of Ecological Engineering, vol. 20, no. 1, pp. 228-237, 2019.

[14] A. Camann, K. Dragsbaek, S. Krol, J. Sandgren, and D. Song, "Properties, Recycling and Alternatives to PE Bags," Project Report, Worcester Polytechnic Institute, 2010.

[15] B. A. Requejo and B. B. Pajarito, "Effect of degrading yellow oxo-biodegradable low-density polyethylene films to water quality," IOP Conference Series: Materials Science and Engineering, vol. 201, article 012004, 2017.

[16] M. Nazareth, M. R. C. Marques, M. C. A. Leite, and I. B. Castro, "Commercial plastics claiming biodegradable status: is this also accurate for marine environments?," Journal of Hazardous Materials, vol. 366, pp. 714-722, 2019.

[17] T. F. M. Ojeda, E. Dalmolin, M. M. C. Forte, R. J. S. Jacques, F. M. Bento, and F. A. O. Camargo, "Abiotic and biotic degradation of oxo-biodegradable polyethylenes," Polymer Degradation and Stability, vol. 94, no. 6, pp. 965-970, 2009.

[18] M. A. L. Nikolić, E. Gauthier, J. M. Colwell et al., "The challenges in lifetime prediction of oxodegradable polyolefin and biodegradable polymer films," Polymer Degradation and Stability, vol. 145, pp. 102-119, 2017.

[19] S. M. Al-Salem, L. G. Papageorgiou, and P. Lettieri, "Techno-economic assessment of thermo-chemical treatment (TCT) units in the Greater London area," Chemical Engineering Journal, vol. 248, pp. 253-263, 2014.

[20] S. M. Al-Salem, S. Evangelisti, and P. Lettieri, "Life cycle assessment of alternative technologies for municipal solid waste and plastic solid waste management in the Greater London area," Chemical Engineering Journal, vol. 244, pp. 391-402, 2014.

[21] S. M. Al-Salem, A. Al-Nasser, M. Al-Wadi et al., "Biodegradable films physical properties change with respect to degradation exposure to various media," in 7th International Conference on Engineering for Waste and Biomass Valorisation, pp. 272-282, Prague, Czech Republic, July 2018.

[22] "Plastics: methodology for assessing polymer photoageing by FTIR and UV/visible spectroscopy," ISO 10640, 2011.
[23] "British Standards (BS) Implementation of the International Standards Organization, Plastics: differential scanning calorimetry (DSC). Part 1: general principles," ISO 11357-1, 2009.

[24] "British Standards (BS) Implementation of the International Standards Organization, Plastics-differential Scanning Calorimetry (DSC). Part 3: determination of temperature and enthalpy of melting and crystallization," ISO 11357-3, 2011.

[25] T. Ojeda, A. Freitas, K. Birck et al., "Degradability of linear polyolefins under natural weathering," Polymer Degradation and Stability, vol. 96, no. 4, pp. 703-707, 2011.

[26] S. Vyazovkin, A. K. Burnham, J. M. Criado, L. A. PérezMaqueda, C. Popescu, and N. Sbirrazzuoli, "ICTAC Kinetics Committee recommendations for performing kinetic computations on thermal analysis data," Thermochimica Acta, vol. 520, no. 1-2, pp. 1-19, 2011.

[27] S. Vyazovkin, K. Chrissafis, M. L. Di Lorenzo et al., "ICTAC Kinetics Committee recommendations for collecting experimental thermal analysis data for kinetic computations," Thermochimica Acta, vol. 590, pp. 1-23, 2014.

[28] "Plastics: thermogravimetry (TG) of polymers - part 1: general principles," ISO 11358-1, 2014.

[29] ASTM International, "Practice for general techniques of thermogravimetric analysis (TGA) coupled with infrared analysis (TGA/IR)," ASTM E2105, 2016.

[30] "Rubber: determination of mass concentration of tire and road wear particles (TRWP) in soil and sediments, pyrolysis GC/MS method," ISO/TS 21396, 2017.

[31] ASTM International, "Test method for elements in water by inductively coupled plasma-mass spectrometry," ASTM D5673, 2016.

[32] "Water quality: determination of selected elements by inductively coupled plasma optical emission spectrometry (ICPOES)," ISO 11885, 2007.

[33] S. Al-Salem, A. Al-Nasser, M. Al-Wadi et al., "Established protocols and research methods acquired in the Waste Management Research Unit (WMRU)," Technical Report, KISR no. 14854, Project Code: P-KISR-06-11, 2018.

[34] T. Muthukumar, A. Aravinthan, and D. Mukesh, "Effect of environment on the degradation of starch and pro-oxidant blended polyolefins," Polymer Degradation and Stability, vol. 95, no. 10, pp. 1988-1993, 2010.

[35] M. Berruezo, L. N. Ludueña, E. Rodriguez, and V. A. Alvarez, "Preparation and characterization of polystyrene/starch blends for packaging applications," Journal of Plastic Film \& Sheeting, vol. 30, no. 2, pp. 141-161, 2014.

[36] ASTM International, "Standard practice for fluorescent UV exposure of plastics," ASTM D4329, 2005.

[37] D. Klepac, M. Ščetar, G. Baranović, K. Galić, and S. Valić, "Influence of high doses $\gamma$-irradiation on oxygen permeability of linear low-density polyethylene and cast polypropylene films," Radiation Physics and Chemistry, vol. 97, pp. 304312, 2014.

[38] L. M. Matuana, S. Jin, and N. M. Stark, "Ultraviolet weathering of HDPE/wood-flour composites coextruded with a clear HDPE cap layer," Polymer Degradation and Stability, vol. 96, no. 1, pp. 97-106, 2011.

[39] M. I. Babaghayou, A. H. I. Mourad, V. Lorenzo et al., "Photodegradation characterization and heterogeneity evaluation of the exposed and unexposed faces of stabilized and unstabilized LDPE films," Materials \& Design, vol. 111, pp. 279-290, 2016. 
[40] R. P. D’Amelia, S. Gentile, W. F. Nirode, and L. Huang, "Quantitative analysis of copolymers and blends of polyvinyl acetate (PVAc) using Fourier transform infrared spectroscopy (FTIR) and elemental analysis (EA)," World Journal of Chemical Education, vol. 4, no. 2, pp. 25-31, 2016.

[41] N. B. Vogt and E. A. Kleppe, "Oxo-biodegradable polyolefins show continued and increased thermal oxidative degradation after exposure to light," Polymer Degradation and Stability, vol. 94, no. 4, pp. 659-663, 2009.

[42] S. Biradar, P. Ravichandran, R. Gopikrishnan et al., "Calcium carbonate nanoparticles: synthesis, characterization and biocompatibility," Journal of Nanoscience and Nanotechnology, vol. 11, no. 8, pp. 6868-6874, 2011.

[43] R. Yang, J. Zhao, and Y. Liu, "Oxidative degradation products analysis of polymer materials by pyrolysis gas chromatography-mass spectrometry," Polymer Degradation and Stability, vol. 98, no. 12, pp. 2466-2472, 2013.

[44] O. Alam, M. Billah, and D. Yajie, "Characteristics of plastic bags and their potential environmental hazards," Resources, Conservation and Recycling, vol. 132, pp. 121-129, 2018.

[45] S. M. Al-Salem, "Advanced technology roadmap development for sustainable engineering practices in tackling waste management challenges," in Third Kuwait International Conference on Life Sciences (KICLS' 2018), pp. 10-11, Kuwait City, Kuwait, November 2018.

[46] D. S. Rosa, C. G. F. Guedes, and C. L. Carvalho, "Processing and thermal, mechanical and morphological characterization of post-consumer polyolefins/thermoplastic starch blends," Journal of Materials Science, vol. 42, no. 2, pp. 551-557, 2007.

[47] S. Al-Salem, "Mechanical and physical evaluation of high content waste/virgin polyolefin blends exposed to natural and accelerated weathering. Volume I: compounding and engineering products from plastic solid waste (PSW)," Final Report, KISR no. 14619, 2018.

[48] E. Yousif and R. Haddad, "Photodegradation and photostabilization of polymers, especially polystyrene: review," SpringerPlus, vol. 2, no. 1, p. 398, 2013.

[49] L. S. Montagna, M. M. de Camargo Forte, and R. M. C. Santana, "Induced degradation of polypropylene with an organic pro-degradant additive," Journal of Materials Science and Engineering A, vol. 3, no. 2, pp. 123-131, 2013.

[50] M. Koutny, M. Sancelme, C. Dabin, N. Pichon, A. M. Delort, and J. Lemaire, "Acquired biodegradability of polyethylenes containing pro-oxidant additives," Polymer Degradation and Stability, vol. 91, no. 7, pp. 1495-1503, 2006.

[51] A. C. Albertsson, C. Barenstedt, S. Karlsson, and T. Lindberg, "Degradation product pattern and morphology changes as means to differentiate abiotically and biotically aged degradable polyethylene," Polymer, vol. 36, no. 16, pp. 3075-3083, 1995.

[52] M. Philip, J. Attwood, A. Hulme, G. Williams, and P. Shipton, "Evaluation of weathering in mixed polyethylene and polypropylene products," Report, The Waste \& Resources Action Programme (WRAP), 2004.

[53] J. V. Gulmine and L. Akcelrud, "FTIR characterization of aged XLPE,” Polymer Testing, vol. 25, no. 7, pp. 932-942, 2006.

[54] S. M. Al-Salem, A. A. Al-Hazza'a, A. A. Al-Rowaih, and F. M. Asiri, "Using scanning electron microscopy (SEM) as a tool for knowhow development in identifying plastic film products originating from solid waste," in Microscience Microscopy Congress 2017, p. 370041, Manchester, UK, July 2017.
[55] S. M. Al-Salem and A. R. Khan, "On the degradation kinetics of poly(ethylene terephthalate) (PET)/poly(methyl methacrylate) (PMMA) blends in dynamic thermogravimetry," Polymer Degradation and Stability, vol. 104, pp. 28-32, 2014.

[56] J. W. Park, S. C. Oh, H. P. Lee, H. T. Kim, and K. O. Yoo, "Kinetic analysis of thermal decomposition of polymer using a dynamic model," Korean Journal of Chemical Engineering, vol. 17, no. 5, pp. 489-496, 2000.

[57] J. W. Park, S. C. Oh, H. P. Lee, H. T. Kim, and K. O. Yoo, "A kinetic analysis of thermal degradation of polymers using a dynamic method," Polymer Degradation and Stability, vol. 67 , no. 3, pp. 535-540, 2000.

[58] M. J. Hato, S. S. Ray, and A. S. Luyt, "Nanocomposites based on polyethylene and polyhedral oligomeric silsesquioxanes, 1-microstructure, thermal and thermomechanical properties," Macromolecular Materials and Engineering, vol. 293, no. 9, pp. 752-762, 2008.

[59] R. Zong, Z. Wang, N. Liu, Y. Hu, and G. Liao, “Thermal degradation kinetics of polyethylene and silane-crosslinked polyethylene," Journal of Applied Polymer Science, vol. 98, no. 3, pp. 1172-1179, 2005.

[60] J. A. Conesa, A. Marcilla, R. Font, and J. A. Caballero, "Thermogravimetric studies on the thermal decomposition of polyethylene," Journal of Analytical and Applied Pyrolysis, vol. 36, no. 1, pp. 1-15, 1996.

[61] S. M. Al-Salem, A. Bumajdad, A. R. Khan et al., "Nonisothermal degradation kinetics of virgin linear low density polyethylene (LLDPE) and biodegradable polymer blends," Journal of Polymer Research, vol. 25, no. 5, p. 111, 2018.

[62] S. M. Al-Salem, B. K. Sharma, A. R. Khan et al., "Thermal degradation kinetics of virgin polypropylene (PP) and PP with starch blends exposed to natural weathering," Industrial and Engineering Chemistry Research, vol. 56, no. 18, pp. 52105220, 2017.

[63] OPA, Types of Degradable Plastic, Oxo-biodegradable Plastics Association, 2008.

[64] A. Aboulkas, K. El Harfi, and A. El Bouadili, "Thermal degradation behaviors of polyethylene and polypropylene. Part I: pyrolysis kinetics and mechanisms," Energy Conversion and Management, vol. 51, no. 7, pp. 1363-1369, 2010. 


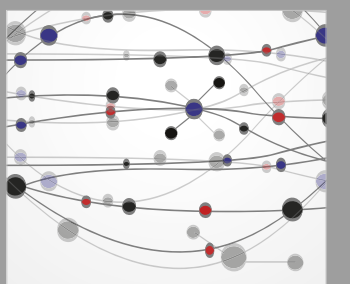

The Scientific World Journal
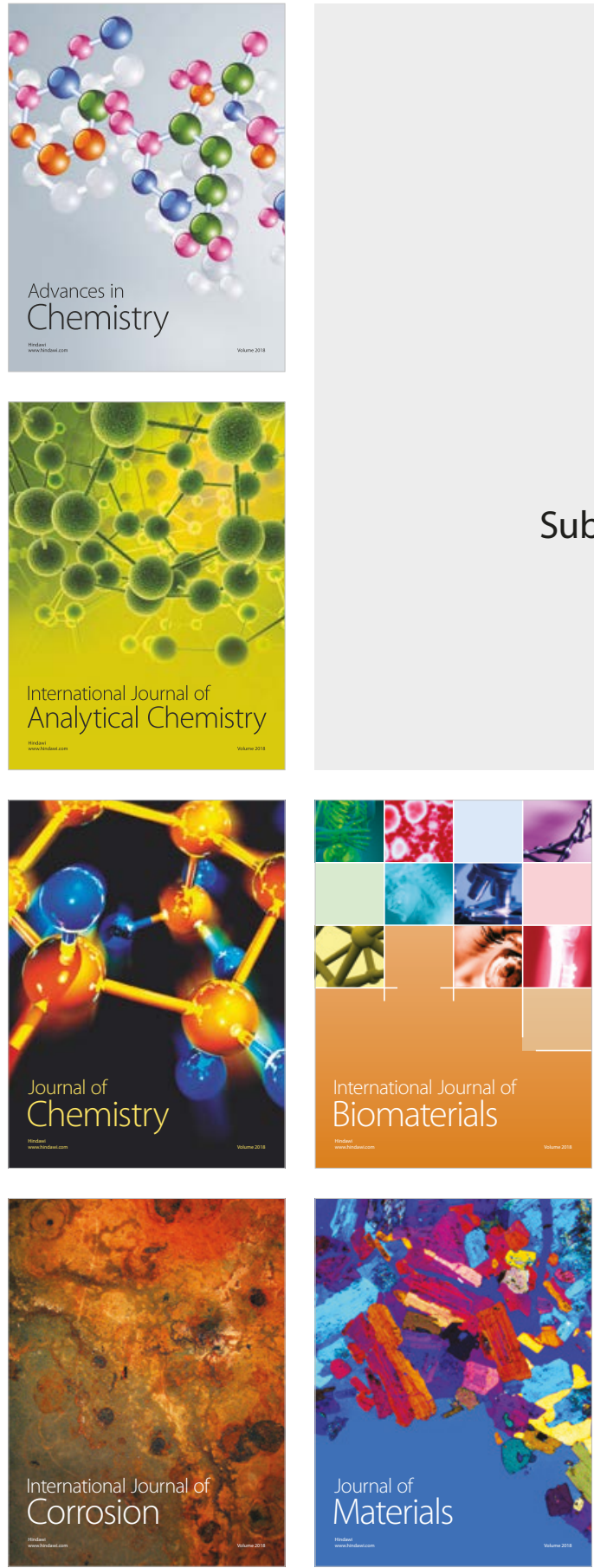

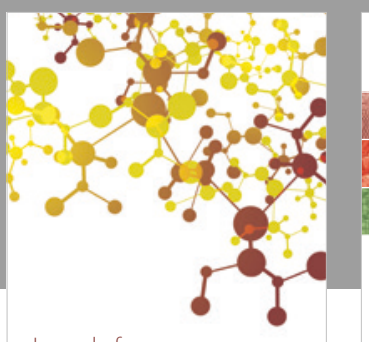

Journal of

Applied Chemistry
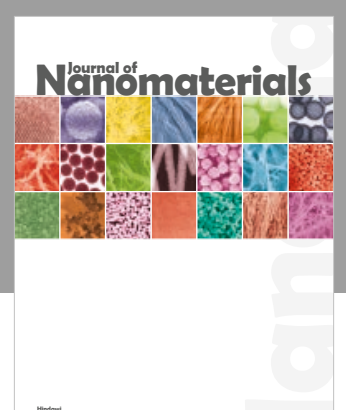

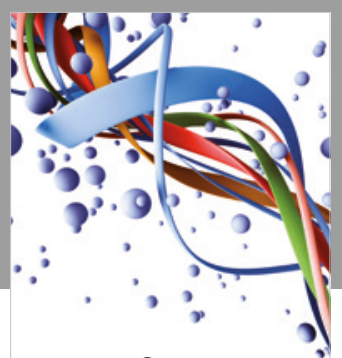

Scientifica

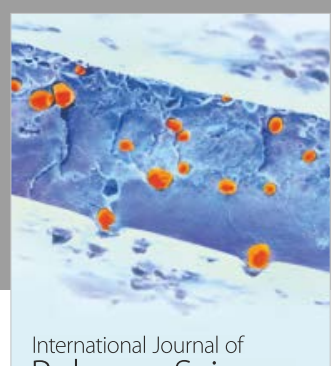

Polymer Science

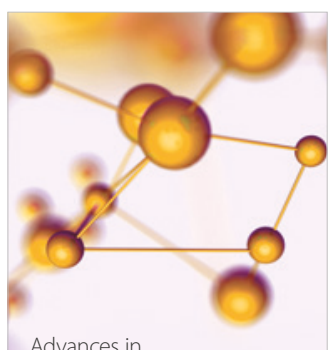

Physical Chemistry
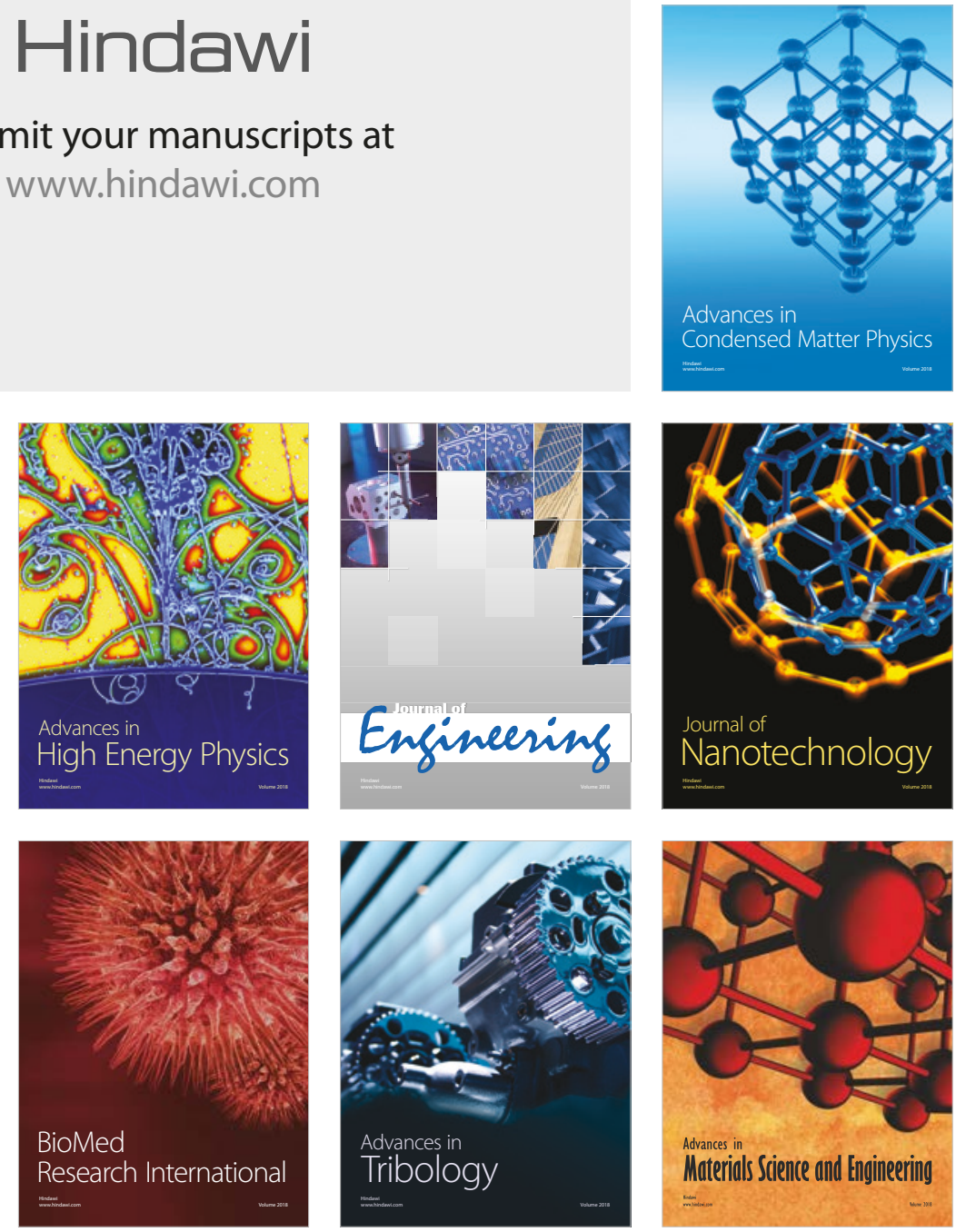